
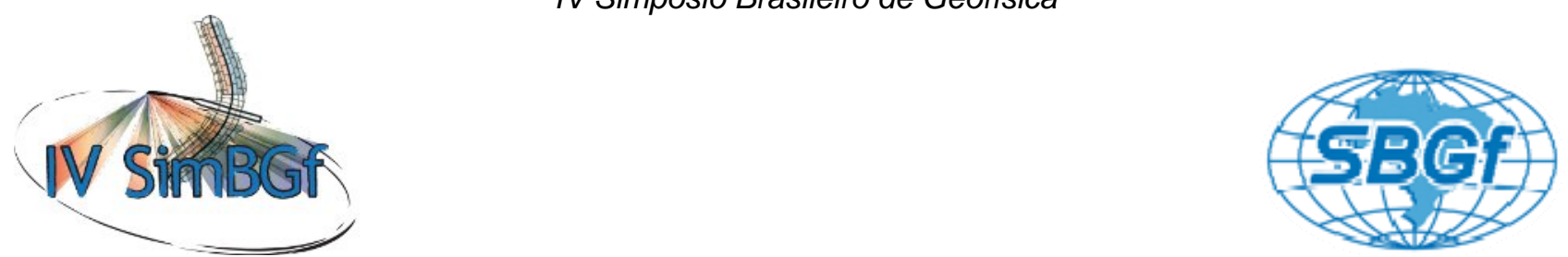

\title{
Realce de anomalias de urânio por regressão múltipla em levantamento aerogeofísico no sudeste de Goiás
}

\author{
Pires, A. C. B.; Vidotti, R. M.; Carmelo, A. C. \\ acbpires@unb.br; roberta@unb.br; chatack@unb.br \\ Universidade de Brasília, Instituto de Geociências - Campus Universitário Darcy Ribeiro - 70.910-900 - Brasília - DF
}

\begin{abstract}
Copyright 2010, SBGf - Sociedade Brasileira de Geofísica
Este texto foi preparado para a apresentação no IV Simpósio Brasileiro de Geofísica, Brasília, 14 a 17 de novembro de 2010. Seu conteúdo foi revisado pelo Comitê Técnico do IV SimBGf, mas não necessariamente representa a opinião da SBGf ou de seus associados. É proibida a reprodução total ou parcial deste material para propósitos comerciais sem prévia autorização da SBGf.
\end{abstract}

\section{Resumo}

Neste trabalho é proposta uma metodologia que aplica a técnica estatística de Regressão Múltipla para avaliar potenciais áreas com concentrações anômalas do radioelemento urânio, a partir de dados aerogeofísicos (magnetometria e gama-espectrometria). A área de estudo abrange parte da região sudeste do estado de Goiás, incluindo os Complexos de Catalão 1 e 2, que apresentam conhecidas anomalias uraníferas. A metodologia apresenta áreas anômalas em função das variáveis independentes, representadas pelas propriedades geofísicas, e dos diferentes litotipos que constituem o ambiente geológico na região.

\section{Introdução}

Atualmente apenas cerca de 50\% da demanda de urânio do mundo é atendida. Poucos países são exportadores ou têm capacidade para suprir suas próprias demandas. O Brasil possui uma das maiores reservas mundiais e com uma pequena parte de seu território pesquisado.

O urânio, metal reativo, apresenta abundância média de cerca de 3 ppm na crosta terrestre. Os minerais mais importantes de urânio são uraninita (pitchblenda), uranoesferita, uranotorita e uranotorianita. Teores médios de urânio em rochas da crosta variam de modo significativo. As menores concentrações médias, inferiores a 2 ppm, estão em rochas sedimentares e intrusivas máficas. As maiores concentrações médias de urânio estão associadas com rochas álcali-feldspatóides intermediárias, intrusivas ou extrusivas, que podem atingir 55 ppm, em alguns casos. Portanto, concentrações anômalas de urânio dependem do tipo de rocha e dos processos de mobilização e re-concentração ocorridos durante a história geológica.

Levantamentos gama-espectrométricos aéreos são ferramentas importantes para a seleção de alvos na exploração de urânio. Contudo, a simples verificação em campo de locais com valores estimados de elevada concentração de urânio pode não ser uma estratégia adequada, em função da variação deste elemento em diferentes litotipos dos ambientes geológicos. $O$ estabelecimento de um teor que represente uma concentração anômala de urânio depende, entre outros aspectos, do litotipo. Concentrações de 4 ppm podem ser consideradas anômalas em rochas sedimentares, enquanto que em rochas graníticas estes valores necessitam ser uma ordem de grandeza maior.

Neste trabalho, propomos o tratamento estatístico de dados gama-espectrométricos aéreos visando realçar concentrações anômalas de urânio dependentes do ambiente geológico em que se situam. Neste contexto, são usados os dados da Área 4, do Aerolevantamento Geofísico de Goiás, que recobre a região sudeste do estado. Este projeto foi conduzido pelo governo de Goiás em convênio com a Secretaria de Geologia, Mineração e Transformação Mineral do MME, com participação do SGB/CPRM.

As técnicas de Regressão Linear Simples ou Múltipla, entre as concentrações estimadas de radioelementos, podem ser usadas para modelar e remover os efeitos de processos geológicos dentro de unidades interpretadas. O modelo de regressão é subtraído dos dados de cada unidade e os resíduos são realçados. O método pode ser útil para remover mudanças sistemáticas grosseiras na concentração dos radioelementos ou para realçar valores que discrepam da distribuição média de teores dentro da unidade interpretada.

A distribuição da intensidade magnética também reflete a distribuição dos litotipos na crosta terrestre. Em baixas e médias latitudes, a amplitude do sinal analítico - ASA pode apresentar resultados satisfatórios para a localização das fontes magnéticas. Esse produto foi utilizado, adicionalmente, para caracterizar a distribuição superficial de litotipos da região.

No presente estudo, a Regressão Múltipla foi aplicada em dados gama-espectrométricos e na amplitude do sinal analítico - ASA com objetivo de realçar concentrações anômalas de urânio em litotipos diversos. O resultado mostra anomalias de urânio evidentes nos Complexos Catalão 1 e 2. Outras anomalias de urânio vinculadas a outros litotipos foram realçadas pelo método. 


\section{Contexto Geológico}

No arcabouço geotectônico da América do Sul, a região em estudo está inserida na Província Estrutural Tocantins (Almeida et al. 1977; 1981; Almeida \& Hasui 1984). É limitada pelos crátons São Francisco, a leste, e Amazônico, a oeste, e pelas bacias sedimentares do Parnaíba e Paraná, respectivamente, a norte e ao sul. A Província é composta por faixas móveis neoproterozóicas estruturadas com a inversão tectônica das bacias marginais meso-neoproterozóicas durante o Ciclo Brasiliano (900-450 Ma), além de núcleos antigos retrabalhados neste ciclo.

Uma das faixas móveis neoproterozóicas incluídas na Província Tocantins é a Faixa Brasília - FDB, sendo composta por rochas supracrustais vulcanosedimentares, intrusões graníticas e corpos básicosultrabásicos subordinados. A FDB dispõe-se na porção oriental da Província e na borda oeste do Cráton São Francisco - CSF, que the serviu como ante-país e é separada a oeste das faixas Paraguai e Araguaia pelo Maciço de Goiás.

A Faixa Brasília apresenta uma extensão de cerca de $1000 \mathrm{~km}$ na direção N-S, desde a porção sudoeste de Minas Gerais até o sul do Estado de Tocantins. Constitui um cinturão de dobras e falhas de empurrão que apresenta, em seu segmento oriental, uma nítida vergência tectônica e metamórfica em direção ao CSF. Suas principais estruturas e cinemática mostram movimento de massa de sul para norte, indicando envolvimento de núcleos rígidos correspondentes ao Maciço de Goiás, a norte. A sudeste, a faixa é recoberta por rochas sedimentaras da Bacia do Paraná. É neste arcabouço geotectônico que está inserida a área de estudo.

As propostas de compartimentação da FDB (Fuck et al. 1994; 2005) foram baseadas na natureza de suas diferentes unidades geológicas e intensidades dos processos deformacionais e metamórficos que atuaram na região. Os principais terrenos são: Zona Externa, Zona Interna, Maciço de Goiás e Arco Magmático.

A Zona Externa é formada por unidades essencialmente metassedimentares com características plataformais (Grupo Araí, paleoproterozóico, e os grupos Canastra, Paranoá, Vazante, Ibiá e Bambuí, de idades neoproterozóicas), típicos de margem passiva. Segmentos de embasamento ortognáissico paleoproterozóico, interpretados como extensão do embasamento do CSF retrabalhados na Orogenia Brasiliana (Fuck et al. 2005), encontram-se expostos a norte desta Zona e em seu setor central (Freitas-Silva \& Oliveira 1999). No extremo norte da Zona Externa, o magmatismo está representado por vulcanismo bimodal e plutonismo ácido do tipo $\mathrm{S}$ que estão relacionados à evolução do rift Araí (Nilson et al. 1994). Na porção central e sul, o magmatismo é ausente ou se restringe a manifestação localizada de intrusões de caráter gabróico.

Quanto ao padrão metamórfico, no segmento oriental da Zona Externa da FDB, o metamorfismo não ultrapassa o grau anquimetamórfico, alcançando fácies xisto verde baixo/médio no seu setor ocidental. Uma tectônica pelicular, com principais estruturas de dobramentos mais suavizados e falhas inversas, constitui o padrão geral de deformação desta Zona (Dardenne 1978).

\section{Dados Aerogeofísicos}

A região em estudo faz parte do "Projeto de Levantamento Aerogeofísico do Estado de Goiás", conduzido pelo Estado de Goiás em convênio com a Secretaria de Geologia, Mineração e Transformação Mineral do MME, com participação do SGB/CPRM (CPRM 2007).

O Projeto teve como principal objetivo oferecer suporte técnico e incentivo ao desenvolvimento do setor mineral a partir do conhecimento de propriedades geofísicas (magnetometria e gama-espectrometria) dos ambientes geológicos em Goiás. Isso possibilitará a identificação de alvos geofísicos anômalos que podem representar descobertas de novas áreas potenciais para pesquisa mineral.

Nos aerolevantamentos realizados, a região sudoeste de Goiás foi recoberta por aproximadamente $60.000 \mathrm{~km}^{2}$ pelo projeto denominado Área 4 - Faixa Brasília Sul (Figura 1). Os metadados referentes ao levantamento geofísico são apresentados na tabela 2.

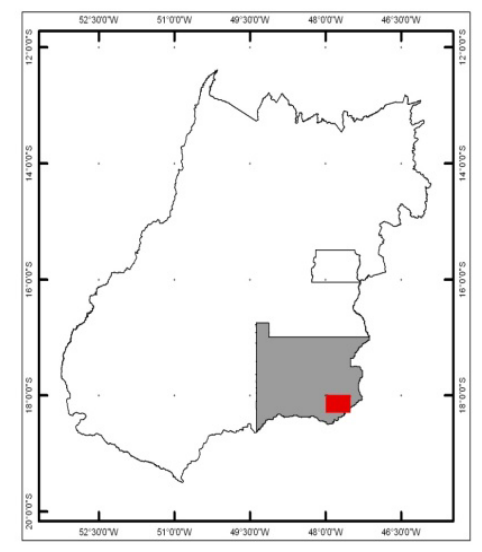

Figura 1 - Mapa de localização; área cinza indica a região do aerolevantamento utilizado neste estudo e a área em vermelho indica o mapa com os resultados na região de Catalão.

Os dados aerogeofísicos foram processados e interpolados com malha regular de $125 \mathrm{~m}$, com posterior geração dos produtos urânio (Figura 2), tório (Figura 3), potássio (Figura 4) e amplitude do sinal analítico - ASA (Figura 5). Na área de estudo, os mapas dos três radioelementos apresentam contínuas áreas com elevadas concentrações destes. Por exemplo, o mapa do urânio (Figura 2), porções oeste e central, mostra extensa e contínua região com elevadas concentrações deste radioelemento. 
Tabela 2 - Dados do levantamento aerogeofísico da Área 4 (CPRM 2007).

\begin{tabular}{||c|c||}
\hline Projeto & Área 4 \\
\hline Código CPRM & 3009 \\
\hline Coordenadas & $-52,50^{\circ}$ a $-48,25^{\circ}$ e $-14,625^{\circ}$ a $-17,75^{\circ}$ \\
\hline Datum & SAD 69 \\
\hline Métodos & Magnetometria e Gamaespectrometria \\
\hline Contratante & $\begin{array}{c}\text { Governo do Estado de Goiás/ SIC- MME/ } \\
\text { CPRM }\end{array}$ \\
\hline Contratado & LASA Engenharia e Prospecções S.A. \\
\hline Período & 03/ 07 a 24/ 11/ 2004 \\
\hline Total de Perfis & $135.756,53$ km \\
\hline Intervalo de & $0,1 \mathrm{~s} \mathrm{(magnetometria)} \mathrm{e} \mathrm{1,0} \mathrm{s}$ \\
(gamastragem & $100 \mathrm{~m}$ \\
\hline Altura de Vôo & $58.834 \mathrm{~km}{ }^{2}$ \\
\hline Área Total & $\mathrm{N}-\mathrm{S}$ \\
\hline Direção LV & $0,5 \mathrm{~km}$ \\
\hline Esp. LV & $\mathrm{E}-\mathrm{W}$ \\
\hline Direção LC & $5 \mathrm{~km}$ \\
\hline Esp. LC & $1 \mathrm{~s}$ \\
\hline Tempo Integração & \\
Gama & \\
\hline \hline
\end{tabular}

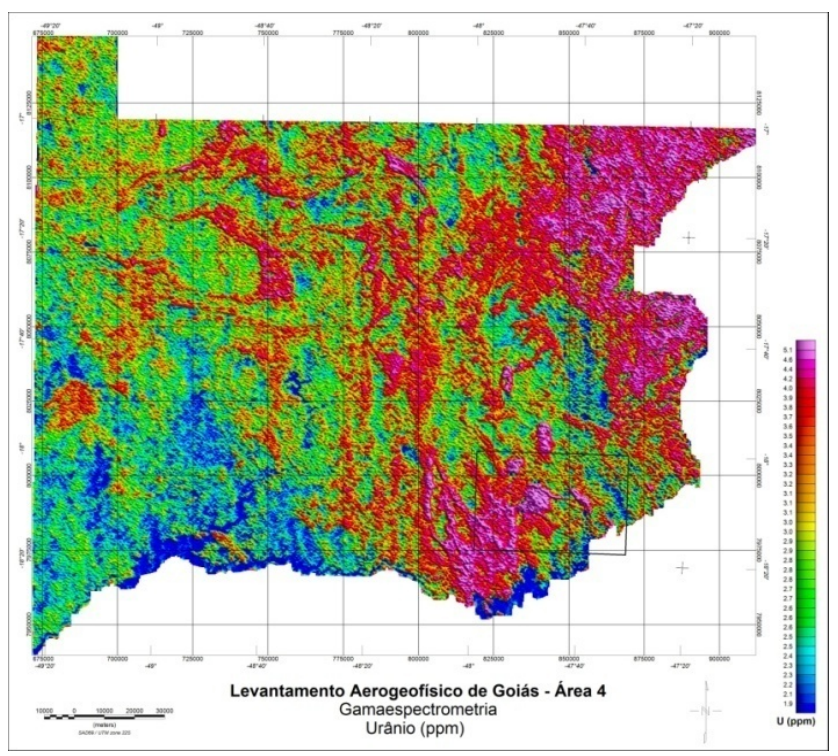

Figura 2 - Mapa do urânio (eU), em ppm. Área de estudo está indicada por retângulo preto.

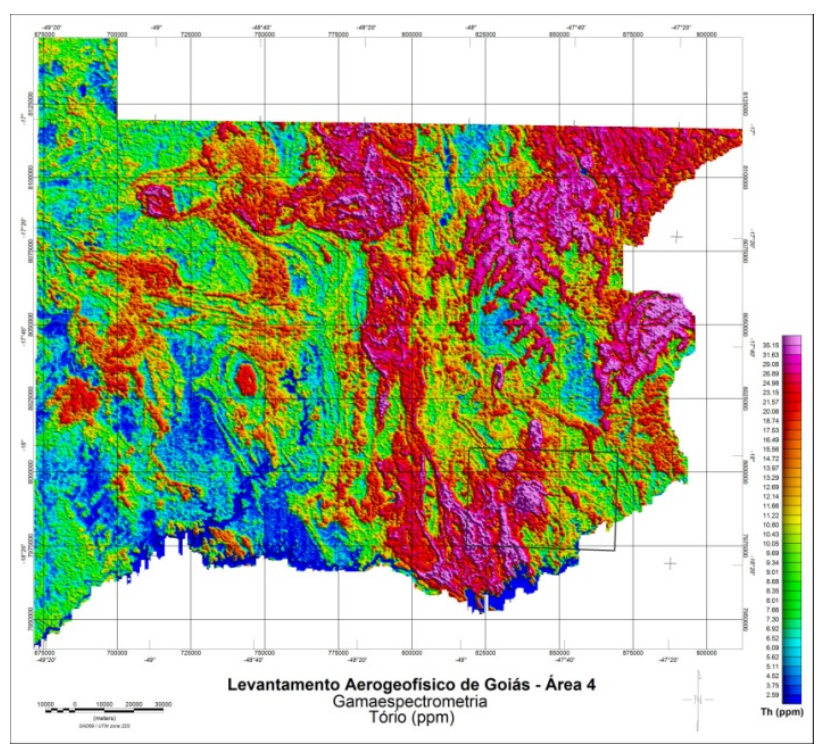

Figura 3 - Mapa de tório (eTh), em ppm. Área de estudo está indicada por retângulo preto.

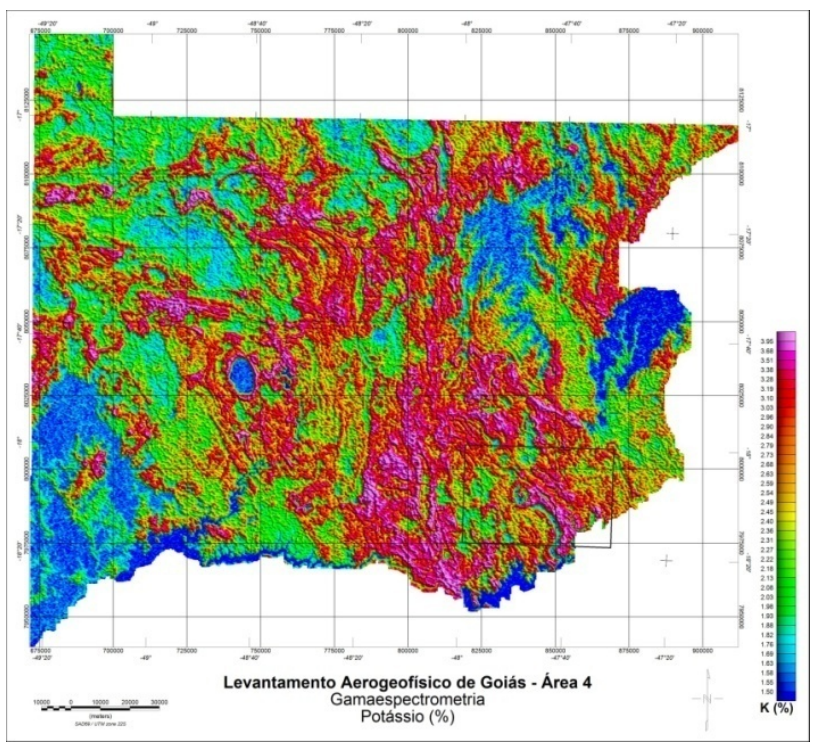

Figura 4 - Mapa do potássio (K) em porcentagem. Área de estudo está indicada por retângulo preto. 


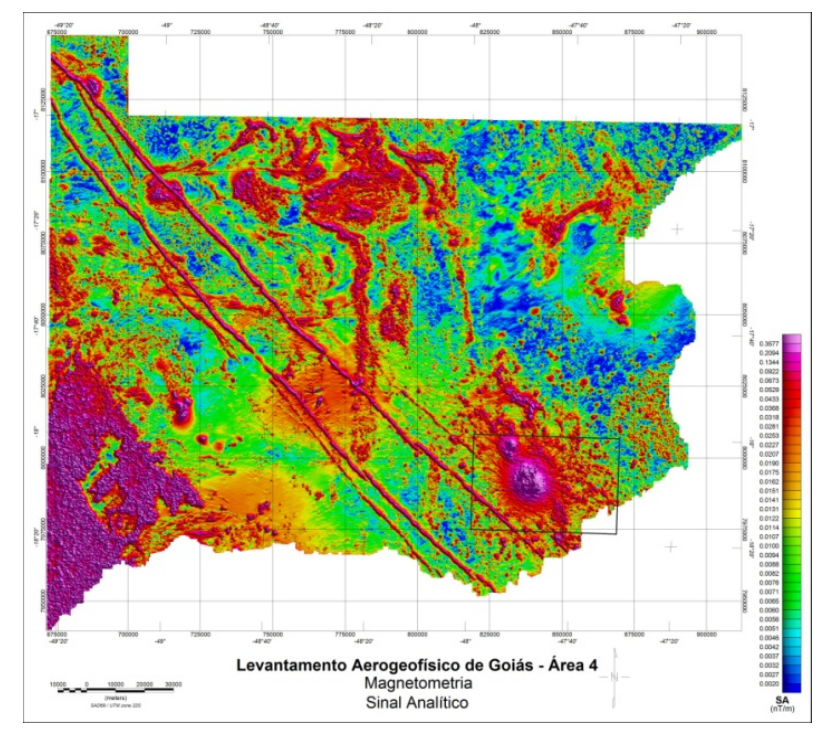

Figura 5 - Mapa de amplitude do sinal analítico - ASA derivado do campo magnético anômalo - CMA. Área de estudo está indicada por retângulo preto.

\section{Metodologia}

A técnica de Regressão Linear, Simples ou Múltipla, entre as concentrações estimadas de radioelementos pode ser usada para modelar e remover os efeitos de processos geológicos dentro de diferentes litotipos. O modelo de regressão é subtraído dos dados dentro de cada unidade, ou conjunto de unidades, e os resíduos são visualizados espacialmente. O método é útil para remover mudanças sistemáticas grosseiras nas concentrações dos radioelementos ou, em outros casos, para realçar valores que discrepam da distribuição média de teores dentro de uma unidade interpretada (Pires 1995; Wellman 1998). No presente estudo, a Regressão Múltipla é utilizada para realçar concentrações anômalas de urânio em diversos litotipos.

Em função de sua pouca mobilidade no ambiente superficial, o tório é considerado com um bom mapeador de litológico (Figura 3) (Pires 1995). O potássio, embora com mobilidade maior, tem uma expressiva presença na crosta sendo um importante elemento maior constituinte de minerais formadores de rochas e, deste modo, indica variada distribuição de litotipos em superfície (IAEA 2003).

A distribuição da intensidade magnética também mostra, em parte, a distribuição dos litotipos presentes na crosta terrestre. A magnetometria tem sido utilizada tradicionalmente como uma ferramenta auxiliar importante para o mapeamento geológico, pois o mapa magnético do campo residual reflete fontes magnéticas próximas à superfície até profundidades de poucas dezenas de quilômetros. Portanto, esses dados não refletem necessariamente a geologia superficial. O padrão da anomalia magnética é complexo pela orientação do campo magnético induzido e pela presença de magnetização residual. As anomalias magnéticas são, então, não normalmente coincidentes com suas fontes. Contudo, em áreas de afloramento do embasamento cristalino com contados quase verticais e magnetização induzida, anomalias magnéticas reduzidas ao polo se ajustam aos limites das unidades magnéticas. Em baixas e médias latitudes a amplitude do sinal analítico pode apresentar melhores resultados. No presente estudo, a amplitude do sinal analítico - ASA foi utilizada para caracterizar a distribuição superficial de litotipos da região (Figura 2).

A normalização dos teores estimados de urânio pelas concentrações de tório (Figura 3), potássio (Figura 4) e a amplitude do sinal analítico - ASA (Figura 5) teria o efeito de reduzir a dependência litológica refletida nos três parâmetros. Uma Regressão Múltipla, tendo o urânio como variável dependente e tório, potássio e amplitude do sinal analítico como variáveis independentes. O mapa do urânio anômalo (Figura 7) representa os resultados da subtração dos teores obtidos no aerolevantamento daqueles estimados a partir da equação de Regressão Múltipla. Isto permite a caracterização espacial de áreas com concentrações anômalas de urânio, positivas e negativas, independentes da distribuição dos litotipos em superfície.

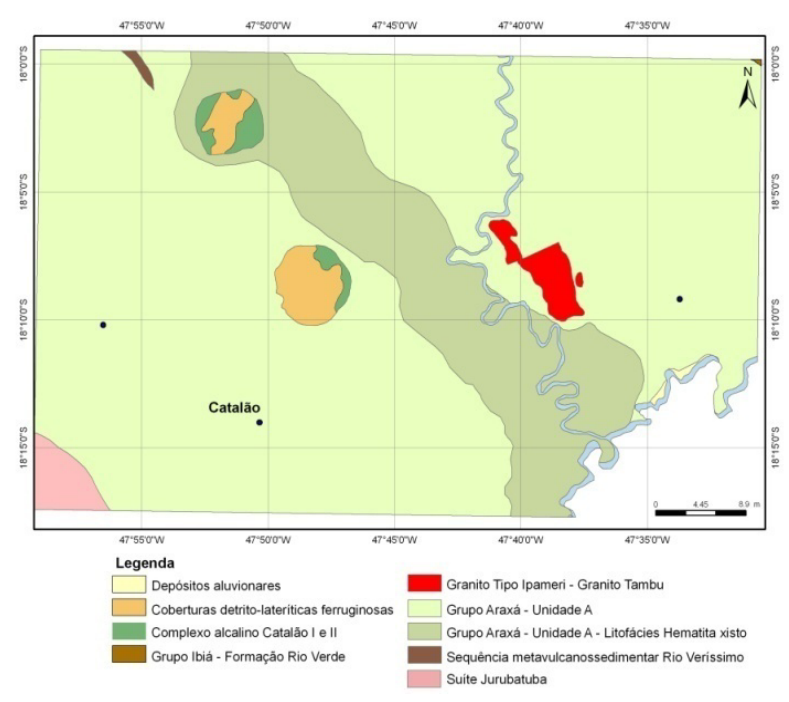

Figura 6 - Mapa geológico da região de Catalão, Goiás (Fonte: Moreira et al. 2008).

\section{Discussões e Conclusões}

A metodologia proposta permite a avaliação automatizada de grandes áreas para a identificação de concentrações anômalas do radioelemento urânio, com realce de anomalias efetuado a partir da subtração do background deste em função dos litotipos (Figuras 6 e 7).

O processamento foi realizado para uma área onde foram indicadas anomalias de urânio vinculadas aos diversos litotipos, em particular detalhe e validação do método 
estão as anomalias de urânio evidentes nos Complexos Catalão 1 e 2 e adjacências (Figuras 6 e 7).

A proposta metodológica se apresenta como uma importante etapa de processamento de dados aerogeofísicos, magnetometria e gama-espectrometria, com objetivo de identificar áreas anômalas para concentrações de urânio. Portanto, na etapa que antecede campanhas de campo, é possível selecionar áreas-alvo anômalas de urânio em função das características geofísicas ou variáveis independentes (potássio, tório e amplitude do sinal analítico), constituindo-se em importante ferramenta prospectiva.

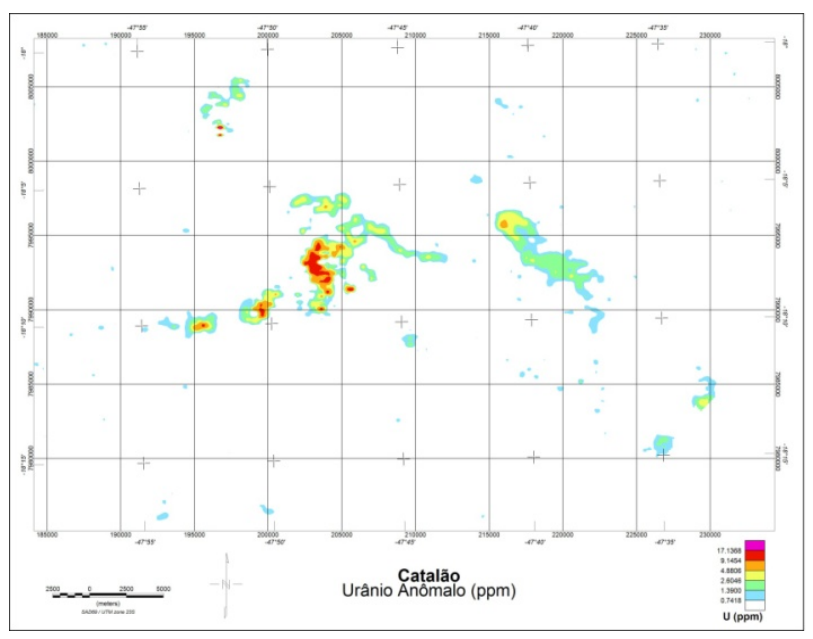

Figura 7 - Mapa urânio anômalo (eU) em ppm.

\section{Agradecimentos}

Os autores agradecem à Superintendência de Geologia e Mineração da Secretaria de Indústria e Comércio do Estado de Goiás pela liberação dos dados aerogeofísicos utilizados neste trabalho.

\section{Referências}

ALMEIDA, F. F. M.; HASUI, Y.; BRITO NEVES, B. B.; FUCK, R. A. 1977. Províncias Estruturais Brasileiras In: SBG, Simpósio de Geologia do Nordeste, 8, Campina Grande, Anais, 363-391.

ALMEIDA, F. F. M.; HASUI, Y.; BRITO NEVES, B. B.; FUCK, R. A. 1981. Brazilian structural provinces: an introduction. Earth Sciences Review, 17:1-29.

ALMEIDA, F. F. M.; HASUI, Y. (Coords.) 1984. O Pré-Cambriano do Brasil. São Paulo, Edgard Blücher Ltda.

CARVALHO, L. M. M.; PIRES, A. C. B. ; OLIVEIRA, C. G. de ; MORAES, R. A. V. de ; BLUM, M. de L. B. 2006. Processamento e interpretação dos dados magnetométricos aéreos do Projeto Itabira-Ferros, MG: uma ferramenta no auxílio ao mapeamento geológico-estrutural e à prospecção mineral. Revista Brasileira de Geociências, São Paulo, 36: 85-92.

DARDENNE, M. A. 1978. Síntese sobre a estratigrafia do Grupo Bambuí no Brasil Central. In: SBG, Congresso Brasileiro de Geologia, 30, Recife. Anais, 2: 597-610.
DICKSON, B. L., e SCOTT, K. M., 1997, Interpretation of aerial gamma-ray surveys-adding the geochemical factors. AGSO Journal of Austaralian Geology \& Geophysics, 17(2): 187-200.

FREITAS-SILVA, F. H. \& OLIVEIRA, C. G. 1999. O arco magmático paleo-proterozóico de São Domingos, GO. In: Simpósio de Geologia do Centro-Oeste, 7, Brasília, SBG, Bol., Resumos, p.4.

FUCK, R. A.; PIMENTEL, M. M.; D’EL-REY SILVA, L. J. H. 1994. Compartimentação Tectônica na porção oriental da Província Tocantins. In: SBG, Congresso Brasileiro de Geologia, 38, Balneário de Camboriú. Anais, 1: 215-216.

FUCK, R. A.; PIMENTEL, M. M.; SOARES, J. E. P.; DANTAS, E. L. 2005. Compartimentação da Faixa Brasília. In: SBG, Simpósio de Geologia do Centro-Oeste, 9, Goiânia, Anais, 26-27.

IAEA - International Atomic Energy Agency. 2003. Guidelines for radioelement mapping using gamma ray spectrometric data, International Atomic Energy Agency, Viena.

MOREIRA, M. L. O.; MORETON, L. C.; ARAÚJO, V. A.; LACERDA FILHO, J. V.; COSTA, H. F. 2008. Geologia do Estado de Goiás e Distrito Federal. Escala 1:500.000. Goiânia: CPRM/SIC - FUNMINERAL.

NILSON, A. A.; BOTELHO, N. F.; FERREIRA FILHO, C. F. 1994. Rifteamento mesoproterozóico do Centro-Oeste de Goiás. In: SBG, Congresso Brasileiro de Geologia, 38, Balneário de Camboriú. Resumos, 258-259.

PIRES, A. C. B. 1995. Identificação Geofísica de Áreas de Alteração Hidrotermal, Crixás-Guarinos, Goiás. Revista Brasileira de Geociências, S. Paulo, 25 (1): 61-68.

WELLMAN, P, 1998, Mapping of a granite batholiths using geological and remotely sensed data: the Mount Edgar Batholith, Pilbara Craton. Exploration Geophysics, 29: 643-648. 